PETER MEYER

\title{
GRAMMATICAL CATEGORIES AND THE METHODOLOGY OF LINGUISTICS
}

van Helden, W. Andries: 1993, Case and Gender, Concept Formation between Morphology and Syntax, Rodopi, Amsterdam - Atlanta, GA, 2 vols., $1280+$ xxv pp.

1. THE SET-THEORETICAL SCHOOL

\subsection{General Remarks}

It is a rare event in the humanities when a scholar accepts the task of presenting, analyzing, and evaluating the entire research work of a certain area in his scientific discipline. However, it is perhaps even more unusual to find that such a survey reopens a discussion just about every historiographer in the field would have declared a closed chapter but that, when reconsidered, shows promising perspectives for future research work.

The monumental two-volume monography Case and Gender by Dutch linguist Andries van Helden is one such event. The book is concerned with the "principles, methods, and empirical work of an East European linguistic tradition which is referred to as the Kulagina School or the Set-theoretical School" (p. 1). One of the major trends in Soviet structuralist linguistics, the Set-theoretical School ${ }^{1}$ consisted of more than 50 scientists - mostly linguists and mathematicians - who were especially interested in certain aspects of morphosyntax, such as the definition and the delimitation of 'case', 'gender' and other notions of traditional linguistics. Although it seems that some of their central ideas can be traced back to the 1920s (p. 1115, esp. fn. 1), all published research work of the school dates from the mid-1950s to the 1970s. According to the author, the abundant work in this field was possible thanks to a "fluctuation in Soviet science policy" (p. 1176) where the exact sciences and mathematical methods had a high prestige among science policy makers who expected pathbreaking new results in automatic language processing and translation.

The most eminent contributors to the school were the mathematician A.N. Kolmogorov as its intellectual initiator ${ }^{2}$, I.I. Revzin as its most prolific thinker, A.V. Gladkij, A.A. Zaliznjak, P.S. Kuznecov, R.L. Dobrušin, O.S. Revzina in the former Soviet Union; for the other East-European countries, S. Marcus (Romania), L. Nebeský, J. Horecký (former Czechoslovakia), A. Trybulec (Poland). 


\subsection{Some Basic Concepts}

Any discussion of van Helden's book requires at least a vague idea of the general methodology represented in it. Since such knowledge cannot be presupposed on the part of the reader, I will preliminarily try to introduce to the reader some basic concepts typical of the Set-theoretical School.

The work of the school was chiefly dedicated to the systematic and formal explication of some central concepts in traditional linguistics, in particular c a s and gender, but also part of speech, paradigm and some others. The exponents of the school were looking for rigorous and cons is tent answers to questions as the famous following ones proposed originally by Kolmogorov (cf. p. 138):

- What exactly do we mean when we say that two words are in the same case?

- How many cases does the Russian language possess?

The answers to questions like these, as were tentatively formulated by representatives of the Set-theoretical School, are usually more or less rigidly formulated mode $1 s^{3}$. In these models, some mathematical primitives, usually sets, or sets of sets, are associated with certain basic linguistic concepts that must be considered somehow given - e.g. the set of sentences of a language L, or the set of nouns in L. These mathematical primitives are then used as a basis for deriving complex formal objects (mostly sets again), which, in the researcher's intention, are to correspond to some more sophisticated notion of grammatical description, e.g. 'case in $L^{\text {' }}$ or 'gender in L'.

\subsection{Example: A Simple Model for 'Case in $L$ '}

For the purpose of familiarizing the reader with the specific kind of intellectual approach so characteristic of Set-theoretical works I will here informally outline a simple example of a model for 'case in a language $L$ '.

Let us assume that the following formal concepts are given as primitives in a description of a specific language $L$ :

1. Set $N$ of nominal lexemes (nouns) in L. Nouns may have different (morphological) word forms; information on these is not contained in $N$.

2. Set $C$ of contexts in $\mathrm{L}$, where contexts might simply be sentences in some phonological representation "with a gap" into which word forms of the nouns in $N$ can be inserted to yield complete, but not necessarily well-formed sentences of L. Let us say that a context admits a word 
form of a noun $n \in N$ provided that the resulting complete sentence is well-formed. Contexts could also be dependency / constituent structures with a 'vacant space' or whatever representation of incomplete sentences is possible in linguistics. Contexts may admit more than one word form of an $n \in N$ or none at all.

3. Function $\mathbf{F}^{4}$, which for each $n \in N$ yields the set $\mathbf{F}(n)$. The elements of $\mathbf{F}(n)$ are sets $F_{1}(n), F_{2}(n), \ldots$ (subindices are given only for convenience), where each $F(n)$ is a set of contexts (i.e., a subset of $C$ ). In the simplest case, each $F_{i}(n)$ is just a set of contexts that all admit the same word form of $n$ (where nothing is said about other word forms of $n$ that elements of $F_{i}(n)$ might also admit). With nouns, however, word form is, as a rule, determined, not only by case, but also by additional factors (gender, number, possessor affixes, sandhi, gender of goveming noun, phonological features...). In this case it is to be assumed that all noun word form conditioning factors except case are already known ${ }^{5}$ then we might say that a $F_{i}(n)$ contains all contexts in which the admitted word form of $n$ can be predicted according to a rule that refers only to the above-mentioned additional factors, but not, of course, to case itself; the rule might be valid only for this very noun $n$. If a context in $F_{i}(n)$, for reasons of 'case syncretism' admits more than one word form of $n$ for a particular combination of the additional factors, then the rule for $F_{i}(n)$ must predict (at least) one of them. Intuitively, the $F_{i}(n)$ are areas of homogeneous morphological coding for $n$.

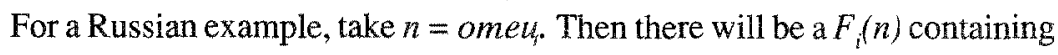
all contexts subject to the following word form assignment rule:

-- SINGULAR [if possible in the context] $\rightarrow$ om $4 y$

- PLURAL [if possible in the context] - omıak

Obviously, there is only one 'additional factor' for Russian nouns, viz. number. Another set, $F_{Y}(n)$, will contain all contexts with the following word form assignment rule:

- SINGULAR [if possible in the context] $\rightarrow$ omua

- PLURAL [if possible in the context] $\rightarrow$ omyos

It should be clear that $F_{i}(n)$ represents, in a way, the dative case of omeu, whereas $F_{j}(n)$ is a 'genitive-accusative' of this noun.

Let us call $X(n)$ the set of contexts not admitting any word form of $n$ (= not appearing in any $\left.F_{i}(n)\right)$.

Let us call a subset $H$ of $C$ homogeneous if it contains, for any noun $n \in N$, only contexts that belong to one particular $F_{i}(n)$, and contexts belonging to $X(n)$. Thus, 
homogeneous sets are sets of homogeneous morphological coding for all nouns. Let us call a homogeneous set $H$ a case if it is maximal, i.e., if the addition of any further context $c \in C$ to $H$ would yield a non-homogeneous set.

This way, we have defined cases as sets of contexts, not as sets of word forms. This has been a common, but not the only possible, practice in set-theoretical linguistics. Note that a context can belong to several cases. In this instance our simple case model cannot tell us which case we are dealing with in a particular sentence. - In order to give the reader a flavour of the kind of mathematical formalism to be encountered in the study, I will present a formalization of the model. Set $\mathbf{H}$ of homogeneous sets in language $\mathrm{L}$ is defined as follows:

$$
\mathbf{H}=\{H \mid H \subset C \wedge \wedge \underset{n \in N}{\wedge} \underset{F \in \mathbb{F}(n)}{\vee} \wedge(c \in F \vee c \in X(n))\}
$$

Set $\mathbf{C}$ of cases in $\mathrm{L}$ is then defined as follows:

$$
\mathbf{C}=\{H \mid H \in \mathbf{H} \wedge \neg \underset{c \in C}{\vee} H \cup\{c\} \in \mathbf{H}\}
$$

A point van Helden does not really stress in his study is that the formalism of a model is neutral with respect to the linguistic interpretation of its primitive components. Thus, take $C$ to be the set of noun lexemes of $\mathrm{L}, N$ to be the set of contexts, and assume $\mathbf{F}(n)$ to contain, for a given context $n \in N$, those nouns of $C$ that are admitted in $n$ or not admitted for ot her than gender agreement $\mathrm{mismatch}$ reas ons. One will see easily that, in this interpretation, $\mathbf{C}$ is the set of genders in L. Other interpretations for the model are not difficult to find; indeed, one could argue that this model formalizes essential properties of grammatical categories in general. The special feature of this model is what I call its descriptive stability. For this, see section 3.3. The problem of additional factors interfering with the concept to be modelled, a problem typical of set-theoretical models, is circumvented in this model, simply because it is relegated to the interpretation of the primitive $\mathbf{F}$, which takes place, if at all, in some other module of a more complete description of the language.

An example will be helpful to understand the foregoing. Take the Russian accusative, which is 'triggered' by, among others, the following contexts:

(1) Я говорю про .....

(2) Я не вижу .....

(3) Я плаваю в.....

The reader will easily verify that, theoretically ${ }^{6}$, any Russian noun can be inserted into (is admitted by) these three contexts appearing in one and the same word form, namely, the form usually called the accusative case form. Idealizing somewhat, let us ignore, for the sake of this example, the existence of plural 
forms for Russian nouns (as well as the existence of pluralia tantum) in order to approximate the 'simplest case' mentioned above, with noun morphology reflecting only 'case distinctions' in a pretheoretical sense of this term. We can, then, conclude that the set containing contexts (1)-(3) is a homogeneous set according to our definition. Now have a look at

\section{(4) Oн находиmcя в ....}

As (3) admits accusative and locative case forms ${ }^{7}$ - with a difference in meaning, of course -, context (4), which exclusively admits locative forms, forms a homogeneous set together with (3), but not with (1) or (2). (2), on the other hand, is the only one of the given contexts to yield a homogeneous set together with

\section{(5) Иван отказался от .....}

To such homogeneous sets further contexts can be added until any further enlargement of such a set would lead to non-homogeneity of the resulting set. These maximal sets, then, are termed $\mathrm{cases}^{8}$. The reader should be aware of the fact that some reasoning along these lines is already understood in such seemingly easy statements as "The nouns of the Latin $o$-declension have identical forms in the dative and ablative singular (plural)".

\section{THE BOOK: STRUCTURE AND CONTENTS}

\subsection{Structure}

The monograph consists of two volumes. Volume I starts off with a preface (pp. $v-x$ ) containing information on the object of the study, its lengthy history that began in $1975^{9}$, too recent publications not taken into consideration ${ }^{10}$, and a brief summary of what van Helden takes to be the major outcome of the study.

On pp. xi-xiii the reader finds an excellent overview of the notational conventions adopted throughout the book. The author numbers "examples / statements", 'formulas / constructs', and 'figures / tables' separately for each subsection, so that, e.g., (3.2.12.10) means 'example / statement number 10 in section 12 of chapter 2 of part 3'. Van Helden makes extensive use of cross-referring; one reason for this is that examples are never repeated within a chapter for the sake of economy. At times, this complicates reading the book considerably, esp. in volume II, so that it will be useful to memorize some often-used examples together with their reference quadrupel numbers.

Some details worth mentioning: all non-English linguistic material is provided with a literal English translation; the Russian examples have been transliterated with full accentuation marking throughout; quotations are always in English - if 
they have been translated by van Helden, they are marked with a dagger symbol $(\dagger)$. References are given in an absolutely systematic and consistent manner and often contain information on the exact location of cited passages or texts referred to, as to chapter or part of the cited publication.

Volume I contains a detailed 12-page table of contents (p. viv-xxv) for both volumes. The main text itself is organized in seven parts. Parts 0-3 are contained in volume I (p. 1-566), parts 4-6 in volume II (p. 567-1200). At the end of volume II, there are three appendices (A-C) on pp. 1201-1221, which will be commented on later, as well as a 46-page list of references and names with some 1500 entries (p. 1222-1268) not even meant to be an exhaustive bibliography but only "the top of the iceberg" (p. xiii). Each entry lists the pages on which van Helden quotes the respective publication ${ }^{11}$ or mentions the respective person.

There is no glossary, but an index of technical terms appearing in the study (p. 1269-78), page numbers referring "to the places where the most user-friendly information about a term is given" (p. xiii) ${ }^{12}$. It should be mentioned that the author often refers back to the first occurence of a term when it reappears in the text, which is certainly helpful for the reader. A very short Russian résumé is found on p. 1279-80.

All in all, the book has been carefully edited. A list of about 120 errata is supplied with the volumes. I found some 60 further minor misprints in the text. Since accuracy in mathematical formulas is essential in a study like this, I have taken special care in checking the mathematics in the book; all errors and misprints in formulas and formal symbols I found are listed in appendix I. In about ten instances I detected serious mathematical inconsistencies.

\subsection{Objectives}

van Helden's study has been designed as a contribution to a general history of Soviet linguistics. In particular, it endeavours to make the huge output of the Kulagina School accessible to a wider audience by removing a number of difficulties that have been deterring linguists from occupying themselves with this short-lived linguistic tradition.

First, the book acquaints the reader with the (well-digested) contents of a wealth of otherwise more or less inaccessible publications. A special feature is the reprint of a paper by V.A. Uspenskij (1957/1993) as appendix A (p. 1201-6). This hardly attainable article mentioned already in note 2 sums up Kolmogorov's ideas on case and plays a crucial role in part 5 of the monograph (see section 2.3.6).

Second, the language of presentation is English. Thanks to the diligent preparation and translation of the example material, which usually stems from East European languages, esp. Russian, Polish, and Romanian, it could be read 
even by someone who only knows English. In view of the linguistic intricacies of the example languages, such a person is still likely to have a hard time finding his way through the book.

Third, the author has been highly successful in developing a unified mathematical metalanguage (as a 'frame of reference') in which all models under discussion are presented. This implies that he had to convert the wildly differing formalisms found in the literature (if any formalization was given there at all!) into his own without altering their mathematical properties - at times a formidable task. This enabled him, and will enable others, to compare different approaches systematically and fruitfully. The mathematical concepts employed are carefully introduced (see section 2.3.2). Usually, formal definitions are preceded by an informal paraphrase that makes the mathematics more comprehensible. Still, it would be pointless (if not plainly impossible) to skip all formulas in reading the book. A penetrative mind and some experience in mathernatics will still be helpful to understand how certain formal definitions actually work.

Fourth, the author thoroughly reviews every single proposal he presents, adduces further linguistic material to find defects in them and to assess their scientific viability in depth. More than once, he proposes sophisticated modifications of existing frameworks and demonstrates their advantages, thereby treating the school "as if it were a living tradition" (p. 5) in order to improve its theoretical foundations.

In sum, even if it takes the reader a minimum of, say, 100 hours to work up the whole monograph, this still does not compare in the least to the almost insurmountable difficulties in obtaining and digesting the original literature, which certainly would not provide him with such a careful comparative assessment as found in van Helden's study.

\subsection{Survey of the Book}

Between 50 and 100 models are introduced and discussed, depending on how one counts the ramifications and modifications investigated, which are numerous especially for the more sophisticated models. It is obvious that none of these can be dealt with in depth here. I shall confine myself to giving an overview of the book in this section and discussing some basic methodological aspects of general interest in section 3 .

\subsubsection{Part 0: The Context}

The introductory chapter (p. 1-137) introduces the object of the study in its broader historical context. The author states (p. 2) that his style of presentation is meant to be anti-presentist, that is, the matter is expounded with, as Russell has 
it, 'hypothetical sympathy', adopting tentatively the historical context of ideas instead of taking the point of view of today's culture and science. Obviously, this is the only reasonable option, since an unbiased 'view from inside' will probably turn out to be a necessary precondition for a sound comparison of the set-theoretical framework to another one. The author consistently adheres to his anti-presentist principle throughout the study.

The socio-economic context is left out of consideration in the main body of the book (p. 5). Instead, the external conditions during the short life of the school are thoroughly illuminated within the context of the history of Soviet linguistics (p. 7-132). The evaluation of this part falls out of my personal competence, however. Suffice it to say that van Helden's lengthy account provides the reader with a profusion of facts (concerning a time span ranging from the beginnings of Marrism up to the present) and with a network of highly original speculations concerning causal interconnections between these facts. It is written in a remarkably broad perspective, with strong personal commitment, pugnacious, seasoned with wit and sarcasm. About 60 pages (p. 39-101) are dedicated to the famous 1950 Pravda debate and Stalin's contribution to it. Perhaps it wouldn't have been necessary to discuss the matter in this depth; nevertheless, the author is able to come up with an original interpretation of the affair, based on some ideas from Vinatrel 1950:

1. Not so much concerned with linguistics, though to some extent successfully pretending to be (Stalin as the корифей всех наук), Stalin's article conveyed directives for the inner party circles and the bureaucracy and propaganda apparatus in an iconically encoded way ('Esopian language', p. 90 sqq.); thus, A.A. Arakčeev, who is often mentioned in Stalin's article, was just an icon for A.A. Ždanov, who had died in 1948; the latter was charged with producing ideology instead of leaving this crucial task to Stalin himself (p. 91).

2. The philosopher G.F. Aleksandrov was the "real sculptor of the Pravda discussion as a public relations event" (p. 100), trying "to play a trick on Ju.A. Ždanov", A.A. Ždanov's son.

Part 1 closes with a short outlook on the study.

\subsubsection{Part 1: Methodological Considerations}

The author's carefulness in questions of methodology is one of the most excellent features of the study. For the most part, in discussions on theoretical problems, all possible alternatives are sorted out and evaluated together with their implications. In part 1 of the book (p. 138-255), which deals with the concept of a 'set-theoretical linguistic model' and the internal structure of such models, a 
particularly large number of concepts are discriminated to yield the backbone of a highly sophisticated methodological discussion.

Basically, the linguistic terminology adopted in such models is liable to a prescriptive, or, altematively, to a descriptive treatment (p. $142 \mathrm{sqq}$ ). In the former case, a fixed 'a priori' system of linguistic terms which are defined with reference to one another is imposed on the empirical data; in the latter case, terminology is constructed to approximate an assumed metalinguistic reality reflected in the data. van Helden does not vote for either option, but proposes to develop a frame of reference within which "an ideal linguistic thesaurus which provides a description of prescriptive systems, a catalogue of models" (p. 147; emphasis mine, P.M.) can be formulated. Within this frame of reference, set-theoretical models are, as a hypothesis, assumed to consist of five components (p. 148) which are discussed from a methodological standpoint in the main body of part 1 .

The first component comprises the technical connectives, which are taken to be representable in notions of set theory and mathematical logic. Consequently, part 1 includes a self-contained introduction into the notions of (naive) set-theory and logic as needed in the study (p. 153-190). This introduction is tailored well to the needs of a beginner, apart from some minor lapses ${ }^{13}$, but is still difficult enough to require careful study. Complex notions are often illustrated in an illuminating way, taking examples from dialect geography to account for some of the most complicated notions (such as 'transitive closure of a tolerance relation', p. 171).

A further component (in van Helden's counting, the fifth), the reality claims of the model, is not described separately, but discussed in relation to each of the other components. Reality claims for a component of a model can be specific or empty, depending on whether some correspondence between the component and "aspects of reality" (p. 194) is asserted or not.

In this connection, the author draws a crucial difference between rel a ti o nal, algorithmic and $\mathrm{calculus}$ models, depending on the reality claims made for the technical connectives (p. 195-8); his definitions remain somewhat vague, however, further discussion being scattered about various places in part 1. Summing up, the following may be said.

1. If the technical connectives (henceforth, TC) simply statically denote abstract relations between concepts of a model, it then is relational. All (primitive or derived) concepts of the model are elaborated in terms of their mutual formal relationships. Van Helden's default interpretation of the set-theoretical models discussed in his study is relational.

2. If the TC describe instructions (say, for a machine) that 'change reality', the model is algorithmic. Take, for example, mechanical discovery procedures 
as discussed in American Structuralism. In algorithmic models, derived concepts can be constructed in a finite number of steps out of the primitives of the theory.

3. If the TC denote the mere possibility of executing a certain process or action in reality, we have to do with a calculus model. In such models, all concepts or notions must be considered given; they are used to derive sentences and can only implicitly be characterized in terms of their respective roles in possible derivations (= sequences of possible processes).

van Helden identifies calculus models with generative grammars and uses this identification as a basis for some very interesting attacks against the generative paradigm. The equation 'generative grammar $=$ calculus model' is plainly false, however, because generative grammars must be able to define a finite procedure (i.e., a procedure rendered by a finite description) to enumerate all sentences of a language (cf. Kratzer / Pause / von Stechow 1973, 41-50), and are thus algorithmic models par excellence $^{14}$; see also Gross / Lentin 1971, esp. 79 sqq. As a consequence, the notion of a calculus model remains notoriously unclear in the study. According to what was said under 3. above, calculus models attribute a status to derived concepts that is not comparable to their status in the other model types. The reader gets no clue about just what a set-theoretical calculus model should look like. The author proposes a so-called deductive hierarchy for model types (p. 248-51) saying that relational models define universal categories of language, algorithmic models identify them for any possible language, and calculus models s p e c if $y$ them for a concrete language. No justification for this hierarchy, which I think is hardly understandable on close inspection, is given. I see no reason why, say, an algorithmic model should not be capable of all three functions named. In fact, this is what the 'principles and parameters' school in Generative Grammar claims to be the case (in a short formula: grammar of a language $\mathrm{L}=$ Universal Grammar $+\mathrm{L}$-specific choice of parameters, the grammar of a specific language just being an instantiation of Universal Grammar). If the author thinks that relational models (for which no accurate definition is provided) are the most general ones, he is possibly right for different reasons ${ }^{15}$. van Helden connects the types of models with different kinds of 'substance' underlying them (p. 196), which, in my eyes, is pure metaphysics, or, even worse, ontology.

The second component is the base component, which contains the primitive (i.e., underived) elements, relations, and (possibly) axioms of the model. It is usually given formally as a system of sets and relations in and between these sets. Base components are differentiated according to whether they belong to a relational, an algorithmic, or a calculus model; whether they are determined extension ally (i.e., as given for a language or set of languages) 
or in tensionally (as characterized only by formal conditions on the objects in them that hold for all possible languages); and whether reality claims for them are specific or empty. Typically, the kind of model studied in the book is relational, with specific reality claims and with an intensional base component.

The third component is the development component. It yields the derivations or definitions of formal concepts that are not present in the base component but can be derived from the sets and relations contained in it. These derivations may be categ ories (as, e.g., 'case' or 'gender') or sets of objects with certain mathematical properties. The crucial question is how 'interesting' or 'useful' derivations can be distinguished from trivial or 'useless" ones. van Helden subsumes the answer to this question under the reality claims of the development component, proposing to take empirical interest as a guiding principle for selecting certain derived concepts as relevant to theoretical inspection ( $p$. 218 sqq.). The empirical interest of a concept is, in turn, evaluated through the linguist's intuition on some "empirical reality' and is equated with the concept's naturalness (p. 221). See section 3.2 for critical discussion. If the base component of a model is viewed as a general theory of (universal properties of) language based, not on empirical data of attested languages, but on general semiotic, biological, or functional principles, then, according to the author, the development component may be seen as an independent, inductively obtained and tested, but deductively working counterpart to it (p. 223, 251).

The fourth component is the stock of $1 \mathrm{abe} 1 \mathrm{~s}$ attached to objects of the base and development components. Labels can be used in a model without reality claims for them - in this case, they cannot be compared to the same labels in another model. If specific reality claims are made for them, as is usually done in set-theoretical models, then labels specify areas of model-independent empirical interest (p. 228-31). Independent of the reality claims put foward, the use of labels may be restricted to concrete, individual systems of sets and relations that form part of the base or development component of a given model (extensional use), or pertain to formal objects as defined model-internally (intensional use) (p. 225 sqq.). In most set-theoretical models, 'case', 'part of speech' and the like are treated as intensional labels with reality claims, whereas, e.g., individual case names are treated as extensional labels without reality claims. It is possible to. constrain the use of a merely extensional label (e.g., "the phoneme /t') to an assignment s pace (e.g., certain articulatory properties to be met by at least one variant of $/ t /$ ).

The author distinguishes full models from partial and substitutional ones. The latter are characterized byindirect reality claims. Partial models contain formal objects in their ba se components that are assumed to be derived somehow from more primitive objects not provided in the partial model. Most set-theoretical models are partial in the sense that they 
are thought of as modules of an all-encompassing full model. Substitutional models contain formal objects that correspond to certain non-linguistic objects of examination (e.g., written texts) that in turn correspond regularly to linguistic phenomena in reality (e.g., concrete utterances).

Models might be classified according to properties of each of the five components (p. 242-4). They can be evaluate d according to criteria of economy, simplicity, consistency, and adequacy. Of these, economy and simplicity, as model-internal criteria, are of limited interest to the author, since they are not applicable to the corresponding phenomena of reality; internal consistency is a necessary well-formedness condition for all models; adequacy is strongly connected with questions of empirical interest.

In the following parts, the author expounds a large number of set-theoretical models, not in a chronological order, but in order of "increasing linguistic sophistication" (p. 255).

\subsubsection{Part 2: String Models}

The base component of a set-theoretical model is assumed to specify the set of possible languages (p. 215). Therefore, it is natural to classify a model according to the relational system its base component consists of (i.e., the sets, and relations within and between these). In part 2 (p. 256-399) of the study the linguistically most naïve and technically simplest models of the school are presented, the so-called string models. Their base component prototypically consists of a relational system $\boldsymbol{Я}_{1}$ :

$$
\mathbf{g}_{1}=(\mathrm{W}, H)
$$

In this definition, $\mathrm{W}$ is an alphabet, that is, a set of basic units. Usually, $\mathrm{W}$ will be a set of (abstractions of) sounds in models for the concept of word, or a set of words in models for case, gender and the like ${ }^{16}$. Note that, in the latter case, the base component formalism does not allow for a notion of paradigm. Thus, in a string model of, say, Russian gender, zópod and zópody will simply appear as two different words; the intuitive fact that these somehow belong together cannot be expressed in the base component.

$H$ is a harp over W, i.e., a set of linear chains or string s of elements of W. If $\mathrm{W}$ contains the words of a language $\mathrm{L}$, then $H$ typically represents the set of 'permissible' or 'grammatical' strings of words in L - in other words, the well-formed sentences in $\mathrm{L}$. This raises a question as to the status of the notion of grammaticality. A very elucidatory discussion is provided in part 2 (p. 266-75) and recurred to at various places in the book. Grammaticality is shown to be a highly instable concept. Provisionally, a notion of broad grammaticality is subscribed to, according to which the semantically deviant phrase $O н$ там 
жил женy is accepted as grammatical on account of the structurally parallel phrase $O н$ mам жил неделю. This conception has the advantage of avoiding having to discuss countless borderline cases.

$\mathrm{W}$ and $H$ being primitives of the model, there is clearly no point in asking where we got these sets. They are simply considered given and used subsequently in deriving the 'target concepts' (p. 236) of the model. These derivations usually resort to istributionalist criteria, as will soon be exemplified.

In chapter 2.1 (p. 276-306) three string models of 'word' are presented and discussed, all of which "have not exactly been successful", evidently because of their linguistic simplemindedness. An attempt is made, in these models, to define 'word' through phonetic phenomena (boundary signals) and distributional properties such as substitutability. These criteria are bound to fail in view of string homonymies ( а в mомаmbl versus aвmomambl), sandhi phenomena and the like. In appendix $C$ (p. 1220-1) a possible formalization of a word definition by Revzin is provided in the form of a giant one-page long formula.

Things get more intriguing in chapter 2.2 (307-371) on word-context feature systems, viz., models in which the words in $W$ (as types, of course) are characterized as to their distribution over contexts. Roughly, a context consists of two strings $a, b$ of words. A word $w$ can be inserted into such a context (between the two strings) to yield a string $a w b$. Now $a w b$ will either be an element of $H$ (that is, a grammatical sentence) or not. For an example, take $a=o н, b=$ интересного уиеного, $w=y в u d е л$. In this case, $a w b$ will surely be an element of $H$. If $w=л ю б и น b$, then $a w b$ will not belong in $H$. Comparing two words $w_{1}$ and $w_{2}$, one could ask

1. whether there is a context admitting both $w_{1}$ and $w_{2}$;

2. whether all and only the contexts admitting $w_{1}$ also admit $w_{2}$;

3. whether the set of contexts admitting $w_{1}$ includes the according set for $w_{2}$;

and so on - to mention but the most primitive cases. Thus, on p. 317-29, Russian nouns are divided into 47 so-called 'families' according to criterion 2 above. These families often unite words belonging to different genders, numbers, and cases. The author empirically rejects a hypothesis advanced by Revzin, namely, that these families directly reflect ('bundles' of) grammatical category features ( $p$. 329-36). Subsequently, the concept of family is replaced by more sophisticated distributional noun classifications that yield a better correspondence to bundles of traditional grammatical features ${ }^{17}$. Examples are taken from Russian and Romanian. All results, however, are far from being satisfactory.

Chapter 2.3 on context-word feature systems (p. 372-99) presents the converse approach, classifying contexts according to which words they admit, as was the case with the model of section 1.3 above. The models presented here prove to be "unexpectedly interesting", as they already deliver the outline of 
a workable case definition. This is surprising, if one takes into account the simplicity of the base component $\boldsymbol{Я}_{1}$. String models have nothing at their disposal except linear strings of words. It follows naturally that there is no way of sorting out interfering factors such as gender or part of speech distinctions when modelling, e.g., case, because string models are unable to 'localize' these factors - neither in the (unstructured) contexts nor in the (uncharacterized) words inserted in them.

\subsubsection{Part 3: Twin String Models}

Part 3 (p. 400-566) discusses an important amendment of the above-mentioned deficiencies of string models. The concept of paradig $\mathrm{m}$ is introduced, which, in most cases, is employed in the sense of "unordered set of words which have an identical lexical meaning" (p. 401). Only now it becomes possible to formally express such simple ideas as "all forms of a noun lexeme exhibit the same gender, but may of course differ in case". S. Marcus has been the only set-theoretical linguist who tried to derive 'paradigm' from a $\boldsymbol{Я}_{1}$-type base component. This turns out to be highly problematic - it would be tantamount to deriving semantics from some rudimentary information belonging entirely to the expression plane of a language (p. 404-10). The only reasonable way is to include the set of paradigms $P$ as a primitive into the base component $\boldsymbol{G}_{2}$ of twin string models:

$$
\mathbf{G}_{2}=(\mathbf{W}, H, \mathbf{P})
$$

Several possible constraints on set $\mathbf{P}$ are discussed and discarded. Of these, the most important one is Kulagina's constraint which demands that no word $w$ $\in \mathrm{W}$ belong to more than one paradigm. Homonymies as бepezý 'I collect' I '(on the) coast' point to the unfeasibility of this constraint (p. 420-2), which is, nevertheless, endorsed through a different interpretation of the sets in $\boldsymbol{Y}_{2}$, taking $\mathrm{W}$ as the set of abstract word forms ${ }^{18}$, which are ordered pairs of a lexical meaning ${ }^{19}$ and a word form. The abstract word forms ('coast', бepezý) and ('collect', бepezý) each form an example of such a pair. Accordingly, $H$ now is a set of strings of such double-sided abstract word forms (hence the name of the model type); the elements of $\mathbf{P}$, viz., the paradigms, are now simply those elements of $\mathrm{W}$ that have a common lexical meaning (= first component). Note that Kulagina's constraint now holds trivially. This reinterpretation of $\mathbf{g}_{2}$ is necessary to cope with the homonymy problem mentioned above.

The author investigates syntax-based twin string models of 'part of speech' in chapter 3.1 (429-49); these face some serious problems, such as auxiliary words, amorphic (uninflected) words, interjections possibly admitted by all contexts, etc.

Chapter 3.2 (p. 450-535) presents twin string models for 'gender'. Not surprisingly, these models are formally closely related to part-of-speech models 
- both model types deal with invariant properties of lexemes. The author presents a demanding in-depth discussion of as many as 18 different gender model varieties, which at times exhibit considerable technical complexity; the chapter closes with an excellent comparative overview (p. 531-3). Several phenomena observed in Slavic languages, in particular the animacy distinction, the pluralia and singularia tantum, and fuzzy gender assignment ${ }^{20}$ present great difficulties, and are thoroughly investigated. As a core problem, certain contexts construable from $H$ must often be excluded from the analysis, as interfering factors produced by them would spoil the results. However, selection of appropriate contexts in order to obtain intuitively satisfactory outputs produces an undesirable sort of implicit circularity; see section 3.1 for more.

The existing twin string case models ${ }^{21}$ (chapter 3.3, 536-66) turn out to parallel very much the string case models based on $\mathbf{\Omega}_{1}$, the paradigm concept being added as an auxiliary device rather than as an integral part of the model that is exploited in full (p. 536). Again, modelling case in terms of word distribution in linear, syntactically unstructured contexts is hardly satisfactory due to the narrow conceptual boundaries of the base component $\boldsymbol{\Omega}_{2}$ : "Contexts suffer from an inherent lack of precision. Of the words that make up a context, only one or two usually affect the case forms of the admitted word: the other words just clutter the picture." (p. 562).

\subsubsection{Part 4: Dependency Models}

In the fourth, longest and most demanding, part of the study (p. 567-1023), a possible solution to the problems just hinted at is developed in all of its possible ramifications, namely, replacing simple-minded linear contexts by dependency structures with a gap ${ }^{22}$. Chapter 4.0 (p. 567-78) introduces the reader to the mathematical properties of dependency structures, paying special heed to different conceptions of projectivity. All set-theoretical dependency models presented in part 4 do not use labelling of the branches or nodes in dependency trees, which simplifies the formal treatment considerably. As in the preceding part, the author first discusses the possibility that the newly introduced base component concept might be derivable from simpler ones.

Chapter 4.1 (p. 579-683) deals with configuration analysis, a quite successless attempt to derive dependency-like structures called subordination structures from simple $\boldsymbol{M}_{1}$-type base components. The starting point of the analysis is the idea that certain chains of words have the same distribution as single words. These chains are called configurations; subsequently, this notion is extended to cover less obvious cases. A formal procedure called configuration reduction produces some sort of immediate constituent structure for the sentences in $H$; furthermore, for each 
constituent its head is derived by yet another procedure in order to derive dependency structures from immediate constituent structures. But in this analysis, 'exоcentric' phrases like на диване already constitute a serious problem since they show a distribution not compatible with their components, in this case, $H a$ and диване. The author systematically confronts configuration analysis with the methodological criticism found in Padučeva (1965). According to both authors, the essential flaw of configuration analysis is the confusion of tokens and types (p. 617).

Of the attempts to derive dependency structure directly, without configurations as an intermediate concept, Nebesky's is the most attractive one, taking $\mathbf{~}_{3}$,

$$
\mathbf{g}_{3}=(\mathrm{W}, H, I),
$$

as base component, where $\mathrm{W}$ and $H$ are as in $\boldsymbol{Я}_{1}, I$ being a highly problematic semantic inclusion relation between elements of $H$. This approach runs into several difficulties, e.g., coordination and non-projective sentences, for which some possible extensions are discussed, viz. surface transformations and the assumption of abstract non-surface elements. However, "no satisfactory dependency structure can be derived from more primitive concepts that are contained in the base components used in Part 2 and Part 3" (p. 683).

Most models include dependency structure as a primitive notion into their base components, which are the subject of chapter 4.2 (p. 684-724). The prototypical base component ${ }^{23}$ of dependency-based models is

$$
\mathbf{G}_{4}=(\mathrm{W}, H, \mathbf{P}, \mathbf{D})
$$

Here, $\mathbf{W}, H$, and $\mathbf{P}$ are the same as in $\boldsymbol{Я}_{2} ; \boldsymbol{D}$ contains, for each sentence $h \in$ $H$, the set $D(h)$ of ordered pairs $\left(\left(w_{1}, n_{1}\right),\left(w_{2}, n_{2}\right)\right)$, where $w_{1}$ and $w_{2}$ are words in $h$ with the position numbers $n_{I}$ and $n_{2}$, respectively, and $w_{2}$ is immediately dependent on $w_{1}$. No model discussed in the study uses all information contained in $\mathbf{Y}_{4}$, simplifying it along one or more of the following lines:

- Linear order is not taken into consideration;

- only possible dependency paths or three- or two-element fragments of such paths are investigated;

- only the possible high or low neighbours of words are considered.

Four models make an effort to derive the notion of paradigm from a simpler dependency base component (chapter 4.3, p. 725-759), using a suspicious semantics-based notion of proto-paradig m that already appeared in part 3 of the study. Questions like Do zópod and ropodá belong to the same lexeme? are really not very likely to be answered in a mechanical way, though. The chapter contains a very interesting discussion of possessive adjectives in Slavic languages. 
Dependency models of 'part of speech', mostly just refined versions of certain string models, are explored in chapter 4.4 (p. 760-834). Though the results seem to offer more prospects than with string models, still several problems remain. In general, the output will be only as good as the researcher's intuition that led to the assumed dependency structures in the base component (p. 831-2). The general assumption, made in these models, of a one-to-one correspondence between word tokens and tokens of lexical meaning conflicts, e.g., with portmanteau and 'semantically empty' elements and the like. van Helden brings in an interesting alternative proposal of his own and doesn't even forget to criticize it thoroughly (p. 813-33).

Chapter 4.5 (p. 835-93) presents two elaborated dependency-based models of case, one of which, namely Gladkij's, is usually "considered the apex of case modelling" according to van Helden (p. 849). But, of course, several problems remain unsolved even here: The base component of Gladkij's model includes only the set of dependency pairs, telling us which words may depend immediately on a given word in at least one sentence in $H$; for any case, Gladkij's definition prescribes that there be a lexical item on which nouns of this and only this case depend immediately; a seemingly simple case as the Russian nominative is, however, probably not in line with this requirement (p. 858 sqq.) - unless we subscribe to a very narrow view on grammaticality, which causes trouble elsewhere in yielding unwanted extra cases. A similar situation is found with gender dependency models (chapter 4.6, p. 894-994); of the two models discussed, again Gladkij's is the more interesting one, being the technically most intricate model of the Set-theoretical School. It takes van Helden as many as 37 pages to introduce it. The model's performance is somewhat impressive, providing intensional definitions of both gender and agreement class ${ }^{24}$. Still it fails to assign token gender correctly in all instances: It would not be able to tell us that cupoma, which is gender-ambiguous in isolation, is not so in ura cupoma (p. 959).

Chapter 4.7 (p. 995-1023) contains a summary of the foregoing and considers a number of possible modifications of the dependency framework, such as labelling dependency branches, inserting abstract nodes into dependency structures, or using a certain dependency format operating with the notion of valency.

\subsubsection{Part 5: Semantic Frame Models of 'Case'}

In several respects part 5 (p. 1024-1175) is the culmination of the linguistic discussion in the study. The three models discussed there have been developed by P.S. Kuznecov, V.A. Uspenskij, and Kolmogorov, respectively; modifications were proposed by Zaliznjak and Marcus. All models include explicitly semantic items in their base component, which, prototypically, looks as follows: 


$$
\mathbf{G}_{5}=\left(\mathrm{W}, K,{ }^{\prime} \mathrm{P} \text { ', 'Q', } M\right)
$$

Here, $\mathbf{W}$ is the set of words (as in $\left.\boldsymbol{G}_{1} !\right), K$ is the set of (linear) contexts, the precise interpretation of which may vary between models (one could have taken contexts to be derived entities, of course, introducing, say, a set $H$ of phrases instead); ' $\mathrm{P}$ ' is the set of (semantic) objects, roughly some kind of abstract meaning of the noun lexemes in the language. "In practice, 'P' corresponds to the set of paradigms" as introduced above in section 2.3 .4 (cf. p. 1026). The elements of ' $Q$ ', henceforth called states in this article, are a kind of semantic correlate to contexts; the exact interpretation varies considerably between models. In Kolmogorov's model, which I will outline briefly below, states (also named semantic frames by van Helden) can be thought of as "states of affairs in the real world" (p. 1027) an object might possibly find itself in at a certain point of time. Thus, a state 'I read $\chi$ ' (that is, the state of being read by the speaker) can be the semantic correlate to a context $\mathscr{A}$ uumaro ....; problems start when we wonder whether this state would also correspond to the context $\mathscr{A}$ иumaю интересную ..... ${ }^{25}$. The answers to questions as these are model-dependent, the problem being that no independent representation (or rigorous definition) of states is available. Finally, $M$ is a relation between $\mathrm{W}, K$, 'P' and ' $Q$ ' telling us for each $w \in \mathrm{W}, k \in K$, 'p' $\in$ ' $\mathrm{P}$ ', ' $q$ ' $\in$ ' $Q$ ' whether the following statement is true: "Word $w$ can indicate object ' $\mathrm{p}$ ' and can be used in context $k$ to express the fact that ' $\mathrm{p}$ ' finds itself in state ' $q$ '." (p. 1028)

Suspiciously, only case models have been produced in the semantic frame paradigm. Of these, the author rates Kolmogorov's to show the best overall performance and, in spite of its being technically simple and among the oldest models of the school, the "linguistic end point" (p. 1142) of the Set-theoretical School. In this model cases are, basically, "sets of states which admit the same word forms" (p. 1124); here, word forms are ordered pairs (w, 'p') with $w \in W$, ' $p$ ' $\in$ ' $P$ '26; a word form ( $w$, ' $p$ ') is admitted by a state ' $q$ ' if and only if there is a context $k$ such that ( $\mathrm{w}, k,{ }^{\prime} \mathrm{p}$ ', ' $q$ ') is an element of relation $M$. The definition can easily be refined to deal with some more or less technical difficulties, which, however, inhibited the model from finding a wider audience (p. 1125-6). Let us look at one example. The states 'There is $\chi$ ' and ' $\chi$ helped me' obviously admit the same word forms in Russian, viz., in traditional terms, they prompt the nominative of each lexeme in the contexts corresponding to them (Ecmb ..... and ..... nомогал/-a/-o/-и мне). Thus, these two states belong to one Kolmogorov-type case. As the reader will have noticed, it is an advantage of these models that they have no difficulties with, e.g., gender interference, since formal changes in contexts have, per definitionem, no impact on case constitution.

Discussion of semantic frame models and their inherent methodological problems is found below, see section 3 . 


\subsubsection{Part 6: The Legacy of the Set-theoretical School}

In part 6 (p. 1176-1200), the huge output of the Kulagina School is synoptically assessed along several parameters: The role of Soviet science policy, internal personal structure of the school, historiography of linguistics, methodology, aspects of formalization, contribution to linguistics and mathematics. This short review is rather modest, with a plea for an overall semantic approach instead of the syntactic is $m$ that prevailed in almost all set-theoretical work. According to the author, the development of an explicit "non-linguistic" metalanguage for statements on language is "methodologically prior" to developing a formal description of a particular linguistic phenomenon (p.1190). I agree that the efforts made to this end constitute the most remarkable achievement of the Kulagina School, which did not set out to invent a new linguistics, but tried instead to find out what linguistics is talking about.

\section{SEMANTICS IN SET-THEORETICAL MODELS: DISCUSSION}

In parts 5 and 6 of his study, the author discusses the role of semantics in set-theoretical models. It is this aspect of his study the author himself deems to be the most important one. By way of synopsis, I shall present and discuss the different options considered in the book and the major conclusions drawn by van Helden.

\subsection{Models without Semantics}

Most of the models found in parts 2 to 4 of the monograph do not include any semantically interpretable notions in their respective base components $\left(\boldsymbol{g}_{1}-\boldsymbol{g}_{4}\right)$, save occasional exceptions where (usually doubtful) semantic auxiliary concepts are introduced to solve specific problems. In the very end, the author rejects the methodological syntactic is $\mathrm{m}$ inherent in these models (p. $1192 \mathrm{sqq}$ ) despite their sometimes impressing performance, arguing (esp. in chapter 4.6, cf. 961 sqq.) that certain complex phenomena can only be accounted for in a primarily semantic approach. As close inspection shows, however, van Helden's arguments are not conclusive. They do not prove that the models are inconsistent or yield the wrong results but only demonstrate that, in certain cases, the obtained results do not exhaust the matter. E.g., no 'syntacticist' model will tell us why in the sentence новую нашёл (uttered on presenting a book - cf. p. 962) the feminine form noвyo is used. But, if hoвую is treated as an adjective, this question clearly is beyond the intended scope of models of gender of nouns. If Hobyro is considered a noun, again no problem arises: Gender models generally don't tell us why, in a certain communicative context, we use one noun (e.g., hosas) 
and not another one (say, новое). ${ }^{27}$ Syntacticist models might be incomplete in that they leave questions open that can only be answered on semantic grounds, but no proof is available that they cannot model the whole range of phenomena within the scope of their respective definitions.

I believe that more fundamental objections against syntacticist models than those advanced by van Helden seem to be conceivable. Even if a non-semantic model (with a base component with specific reality claims) handles all data of a specific language 'correctly', there will be, to my conviction, no possibility to guarantee the same, as soon as the model is applied to another language. Even the most sophisticated non-semantic case models to be found in the study will obviously meet with complete failure when applied to other than, e.g., Romance or Slavic languages. Take Kwakwala (Wakashan), which has become famous among morphologists for cliticizing case and definiteness morphemes on the (phonological) word prece ding the respective noun (Boas 1969, 528-30). None of the models in parts 2-4 could handle this phenomenon. If anything, only a considerable reinterpretation of the base component elements and the use of several auxiliary concepts could save the approach. Note that the very concept of linear context will have to depend on the language described.

Most case models discussed by van Helden have problems with 'filtering' gender inference in, say, Russian. But even if a model has been amended so as to surmount this difficulty, it will, again, produce utter nonsense when confronted, with, e.g., Modern Irish. Taking Irish nouns that are attributes to other nouns in a 'possessive construction' as an example, we may state that their morphological form may depend on the following parameters (cf. Ó Siadhail 1980, passim, for the Cois Fhairrge (Connacht) dialect; Christian Brothers 1991, 15-6, 28-32 for Standard Irish): definiteness and referential properties of the nomen rectum; the word immediately preceding it; case, number, gender, (deep-)phonologica ${ }^{28}$ and word class properties of the nomen regens. Actually, things are even more intricate due to interfering semantic and syntactic factors. I presume a model that encompasses, or rather foresees, all possible horrors of morphosyntax is not possible, unless it is as general, and, eo ipso, trivial as the one proposed in 1.3, which has the inestimable virtue of leaving all categorial unravelling to 'some other module'.

Tentatively, I would like to advance the following principle: Successful set-theoretical modelling of any morphological category $M$ in a language $\mathrm{L}$ presupposes exhausting knowledge of all other grammatical categories in $\mathbf{L}$. Note that this principle was adopted above in 1.3 in interpreting the linguistic content of $\mathbf{F}$. Such knowledge will, e.g. in highly fusional morphological systems, indirectly require that the investigator already know a good deal about $M$ and its morphological expression. Yet, this kind of circularity is not a deathblow to set-theoretical models. It is closely connected with another, epistemic circularity: 
Applying a model with specific reality claims to a language, it can occur to the investigator that the results are, from a linguistic point of view, devoid of what van Helden calls empirical interest (p. 218-21). In this case the investigator has at least two options. He may alter the empirical correlates of base component notions (using, e.g., refined dependency structures); or he may try to find a better derivation for the target concept. In choosing the former possibility, he shows us that his intuitive expectations will condition his interpretation of the base component elements, and, eventually, the results he obtains (p. 831-2); in choosing the latter, the evaluation criterion for derivations is empirical interest, which the author equates to naturalness or metalinguistic intuition as a characterization of pertinent psychological states of a linguist (p. 218-21). In either case, intuition shapes the model in order to yield intuitively right results. Again, contrary to what the author seems to believe, this epistemic circularity does not endanger the set-theoretical project, at least if we subscribe to a strictly relational interpretation of the models, where different concepts are linked by a network of mathematical constraints and are thus determined-modo structuralistico- only by their respective positions in a system. Van Helden slips into the algorithmic paradigm when he speaks of categories "we get out of the model" when we "feed" it in a certain way (p. 832). There is obviously no way to get rid of epistemic circularity, which may even be argued to be present in any scientific model (for physics, cf. Weizsäcker 1988). To my mind, we can even make a virtue of necessity by re-interpreting set-theoretical models as necessary conditions: No putative grammatical (or morphological) category $C$ of a language $L$ may be called case unless $C$ can be shown to be expressible in terms of set-theoretical formalism XYZ. Another option of interpreting set-theoretical models will be hinted at in section 3.4.

\subsection{Models Employing Mainly External Semantics}

The models discussed in part 5, among them Kolmogorov's, use states as unanalyzed semantic primitives. Van Helden investigates the option of further dissecting states into more elementary 'meaning factors' relevant to the case (or, more generally, word form) of words admitted by these states. A meaning factor contained in a state ' $q$ ' is said to be internal if it cannot be correlated with any formal properties of a context $k$ corresponding to ' $q$ ', but only with the forms of words admitted by the state; otherwise it is external (p. 1142-4). Thus, if a context $k$ completely determines, by virtue of its formal properties, the case of words admitted by it, we must assume that the corresponding state ' $q$ ' contains only external meaning. This last thought, incidentally, shows that all non-semantic models (as discussed in parts 2-4 of the study) happen to operate, if indirectly, on external meaning! In general, the internal vs. external distinction 
is not an absolute one, but hinges upon the linguistic model within which the notion of 'context' is determined. Thus, if one takes contexts to be linear strings "with a gap", the context

$$
\text { даю ..... }
$$

will admit word forms of at least three (traditional) cases, the choice between which is ascribed to internal meaning. If contexts are given as dependency structures formally distinguishing different valencies of a given verb (cf. p. 10135 ), then the above linear context will correspond to at least three dependency contexts admitting only forms of one case, respectively. This way, we can eliminate internal meaning by small steps by turning it into the external meaning of refinedly described contexts. Again, intuition won't help: Though it seems natural to think (as van Helden does, p. 1144) that the choice between genitive and accusative in

\section{Я не люблю .....}

is governed by internal meaning, Pesetsky $(1982,147$ sqq.) assumes two widely differing syntactic descriptions of the context. - In the following I will assume the matter to be settled somehow.

The author rejects models founded on external meaning for two reasons (p. 1172). His criticism concerns primarily 'state models' such as Kolmogorov's, since states contain external meaning, if amalgamated with internal meaning. To my mind, his counterarguments are inconclusive.

First, van Helden claims that state models produce intuitively undesirable cases. Thus, in a variety of Russian, the context

\section{Трудно ходить по......}

admits the (traditional) "dative for most nominals but the locative for pronouns of the third person and for interrogative pronouns" (p. 1092). This suffices for a new 'po-case' to come into being in, say, Kolmogorov's model ${ }^{29}$. Intuition is given as the major reason to reject this descriptive solution (p. 1114), which is the author's common practice in assessing set-theoretical models. But perhaps we should say that it is a task of linguistics to find out just why a certain solution appears counterintuitive. In the po-case, the problem may be called 'want of generalization'. Assuming a po-case obscures the simple fact that po governs the dative in certain contexts save with a clearcut closed class of words. A solution seems to be more appropriate where a local rule handles the few exceptions, interacting with a global rule of dative assignment after po. But, of course, no notion of 'rule' is available in set-theoretical models. Alternatively, we might say that it is preferable not to take into account the few exceptional words, by, e.g., assigning them to a different word class than nouns. But the problem of 
which other data must be taken into account in describing a concrete phenomenon is not specific to state models; instead, I propose to view it as one of the most fundamental questions of linguistics at all. To take a familiar example: Must we, in describing the syntax of passive clauses, take into account the 'corresponding" active clauses (as early generativists firmly believed) or not (as many of today's Chomskianists would argue)?

Indeed, it is exactly this general methodological problem to which van Helden's second objection against state models can be reduced, viz. that they cannot distinguish between case homonymy and syncretism. The author holds it to be plausible that in

\section{(1) Он плавает в море}

the word mope is ambiguous between an accusative and a locative reading due to an accidental coincidence on the expression plane (p. 1138). In contrast to this, omua in

\section{(2) Я не вижу отиа}

is supposed to be an instance of case syncretism: With all animate nouns and their modifiers, the choice between accusative and genitive in direct objects of negated verbs, a choice usually assumed to have semantic import, is completely neutralized on the expression plane. van Helden reports that native speakers feel no ambiguity here, which proves nothing in itself, given the possibility, often mentioned in the study, to condition informants accordingly. The author declares the homonymy vs. syncretism dichotomy a crucial one; now, linguistic dichotomies are good at disappearing once closely looked at. This particular one can easily be subsumed under the general question of linguistic description formulated above. To account for the homonymy of (1), it would suffice, for some $^{30}$ grammarians, to take into account some "close relatives' of (1), viz., sentences where mope is modified by an attributive adjective. Things aren't that easy with (2). If we want (2) to be homonymous we must presuppose that, e.g., $\not{A}$ не вижу книгу / книги are relatives not too distant from (2) to be taken into account and be treated analogously. Such a presupposition is based on the linguistic world view chosen, rather than on a priori considerations on human language. Note that linguists are even free to refuse all consideration of the behaviour of other nouns when determining cases of a nominal lexeme. In this instance, we get lexically determined case systems with cases valid for one particular noun only. Interestingly, the author discusses this option at great length, despite of its admitted clash with tradition (p. 1135 sqq., 1156 sqq.).

Thus, on the one hand, some alleged flaws of state models may turn out to be thomy for any linguistic model. On the other hand, more defects are lurking in the morphosyntactic dark, possibly more fundamental ones. First, state models forget 
about the virtues the author ascribes to them as soon as we leave the realm of Slavic and Romanic. Kolmogorov's model copes well with gender interference in Russian, but is really helpless in Irish, where 'genitive' noun word forms sometimes depend on the gender of the preceding noun. In Standard Irish, the states 'It happened on a day of $\chi$ ' and 'It happened on a night of $\chi$ ' would belong to different state model cases, as oíche 'night' (but not lá 'day') is a feminine noun, causing the following word to undergo mutation of the initial consonant. Perhaps the model could be amended in order to cover the relevant data correctly, but it is improbable that any model could capture all complications possible in human language mechanically.

Further, external meaning in states have a doubtful conceptual status. If a meaning factor is external, it is, as said above, correlated to some formal property of a context. Why, then, don't we just talk about contexts instead of states? ? $^{31}$ Well, if every formal difference in context corresponded to a difference in state, a Kolmogorov-type model would, mathematically, become identical to a linear string model. As the discussion of states in the study shows, they are a valuable instrument simply because they are assumed to represent semantically the factors that are relevant for choice of case. Two questions arise: If prepositions or verbs govern a certain case, do we need semantic states to account for this? And, what is worse, do we need the states we posited to model case for anything else than modelling case? The second question hints at a deep-rooted circularity that jeopardizes Kolmogorov's enterprise, since even if we accept, as I did above (section 3.1), that we get cases according to our intentions and intuitions as reflected in the base component (in this instance, in the states), we can't possibly admit a situation where a primitive of the model has no independent justification apart from helping us model our target concept. Paradigms or dependency structures in non-semantic models are obviously relevant for other problems besides case modeliing; as far as I can see, this is not true for states.

\subsection{Models Employing Internal Semantics}

The last resort, then, is internal meaning: meaning factors that correspond to formal properties, not of the context, but of the word inserted into it. As appendix B of the study (p. 1207-1219), an earlier article by van Helden (1979) is reproduced in which an internal semantics approach is formally worked out to a certain extent. In the article, a set of semantic atoms is considered given, together with relations between them; any linguistic sign is assumed to be a linear phoneme string paired with a semantic configuration, i.e., a set of semantic atoms with relations between them. The paper is extremely thought-provoking, containing attempts of defining linguistic signs, words, inflection classes etc., but 
is somewhat flawed by a particularly high number of errors (see appendix); it contains several debatable assumptions ${ }^{32}$, most of which could perhaps be dropped in a more sophisticated version the author promises for future publication. In the paper, an effort is made to define the notion of $\mathrm{g}$ rammatical category purely in terms of internal meaning. Roughly, the semantic configurations that are the members of a grammatical category must form a set of mutually exclusive alternatives in the more complex configuration they form a part of. This idea is programmatically developed and refined in part 5 (p. 1151 sqq.), where special attention is drawn to semantic feature systems of case (modo Jakobson) and lexically determined internal case systems. The mode of exposition in this central section of the book is unbearably inexplicit, sometimes even cryptic; thus, I found myself unable to find a coherent understanding of the crucial characterization of 'internal grammatical category' (p. 1151, lines 12-7 from bottom) ${ }^{33}$ that is compatible with the remarks on establishing invariant meaning on p. 1160-1, the 1979 paper, and a host of remarks on other pages ${ }^{34}$. Apart from detail questions, the following problems arise.

First, if a definition of case or grammatical category is based on internal meaning alone, we may wonder whether any connection to expression plane phenomena remains. Indeed, the author assumes precisely no connection whatsoever in his 1979 paper. Things are seemingly different in the main text of the study. On p. 1156, fig. 5.66.1 shows lexically determined case systems based on internal meaning for three lexical items, where the internal case inventory of each noun is in one-to-one correspondence with the word forms distinguished by the lexeme. Only three pages later, deviations from this simple scheme, such as instances of 'case syncretism', are acknowledged to remain problematic. But why should differences in word form be paralleled so neatly by semantic differences? van Helden assumes more or less explicitly ${ }^{35}$ that a kind of invariant abstract meaning common to each feature of a grammatical category (sc. found in traditional grammar!) can be found unless the meaning is 'neutralized' by purely external conditions actualizing that feature mechanically in a certain grammatical context (cf. p. 1196-7).

This is not the place to discuss the old question of justifying invariant underlying meanings of grammatical categories. Let me mention a potential counterargument that is particularly pertinent to the set-theoretical approach. Imagine you just managed to assign a single abstract meaning to what you believe to be, say, a certain case in the investigated language, a single meaning that accounts for all non-externally conditioned occurences of this case found so far. As soon as you find a single counterexample to the alleged common abstract meaning you are urged to find a new, even more abstract meaning subsuming the new data. As a consequence, your theory of the abstract case meaning is descriptively instable as a single additional datum might prompt a 
major theory revision. This descriptive instability is typical of set-theoretical models: In many case models, a single noun with strange behaviour can produce new cases. Note that the model proposed in 1.3 above avoids this kind of instability: Local irregularities can be filtered out by a fitted adaptation of function F. This trick does not really solve our problems, of course; instead, it suggests that a solution must be sought outside the formalism, perhaps in a semiotic approach.

Even in an internal meaning approach to grammatical categories, external meaning must be taken care of. If there were, in a language $L$, a noun two different word forms of which are always conditioned exclusively by (different) external conditions ${ }^{36}$, this noun alone would force us to reject the internal meaning approach (cf. p. 1152-4). Some old friends, such as the po-case discussed above, turn up again. A po-case in Russian is avoidable in an internal meaning approach to case only if we assume that case after $p o$ is conditioned by external meaning. I do not believe that this captures the reason why we, intuitively, would rather like to abstain from a po-case. But if we accept the word forms after 'local' po as conditioned externally, then it is unclear to which of the internally defined cases they belong. A procedure of extrapolation will have to be called for to assign the "relevant grammemes" here (cf. p. 1152); but I doubt whether this can be achieved in a non-arbitrary way.

Inspired by some ideas of Mel'čuk, van Helden proceeds to present what is announced as the principal result of his study at the very outset (p. ix): After the extension of language-specific grammatical categories has been established on grounds of internal meaning, specific grammatical categories (such as case, gender etc.) of a language can be identified only in reliance on external meaning. Thus, van Helden proposes that a category can possibly be assigned the label case, if it may be used to "mark the second place in a valency relation" (p. 1173), whereas the formal means of a gender category are never used to this end. As a result, so-called assignment spaces for category labels can be given by referring to conditions of external meaning.

Again, there are objections, the discussion of which would require a separate article. But, naturally, the notion of valency is crucial here. Imagine a language where nomina recta in the genitive case mark the gender of the nomen regens, which is a common phenomenon (cf. Mel'čuk 1993). If the governing noun is an inherently relational noun, that is, if it is "inalienably possessed", nouns dependent on it will get in the second place of an obligatory valency relation, and therefore, the gender marking of the nomen regens found on them will mark exactly this second position. It is implausible to assume a reinterpretation of gender as case here. Generally speaking, there are possibly differences between case and gender that are more fundamental to grammatical modelling but not expressible in van Helden's framework: Case seems to be a feature of nouns 
as token noun phrases, whereas gender is likely to come out as a feature of nouns as lexemes. Note, incidentally, that it is not impossible to model such a characterization in set-theoretical terms; but it would urge us to extend our analysis beyond the level of single words.

It is even conceivable that the enterprise of finding an assignment space for the labels 'case' or 'gender' will turn out to be of minor importance. A description of a grammatical category in a language might be a good description even without providing a label for the category described. It is quite possible that the common properties of what we are inclined to call case in different languages happen to fall out of the scope of a formalizable description of grammar, because they can be accounted for only on a more fundamental, say semiotic or cognitive, level.

\subsection{Conclusion}

I can only mention some other aspects that deserve careful discussion. A full-fledged set-theoretical account of categorial phenomena would have to embrace language change as a part of its descriptive power. For the time being, diachronic changes remain a mystery for set-theoretical models, especially for models employing semantic notions, because they potentially affect different, semantic and non-semantic primitives of the base component at the same time; these different changes in the base component (e.g., in states and paradigms), however, are interrelated, without these interrelations themselves being amenable to set-theoretical modelling.

Idioms are a case in point. Being the result of diachronic petrification, expressions like "kick the bucket" possibly resist any semantic analysis, which jeopardizes semantics-based set-theoretical approaches that would have to give a semantic interpretation to 'bucket' in order to assess its case. In fixed expressions, extinct morphology might be conserved - which lets us hasten to try excluding them by way of operational principles from our analysis.

Embracing Chomsky's opinion that discovery procedures are not possible (cf. 1957, 56), I suggest that a much weaker interpretation of set-theoretical formalization is more feasible. Briefly, we can imagine to look at a set of possible descriptions of a certain language. Our set-theoretical procedures, then, might turn out to be statements on possible transformations of descriptions into other descriptions, some of which can be assessed as being more natural, predictive, or economical than others only by description-external criteria. This view, though unspectacular, still does not turn set-theoretical models into trivia; only by a principled discussion of semiotic and communicative properties of human language can it be justified.

My lengthy remarks are not meant to spoil the overall picture of van Helden's study. Rather, they show that it is an excellent and thought-provoking stimulus 
for further research work, which I believe is about the best praise a scientific publication can be given. The methodological, empirical, and historiographic scrutiny of this giant work as well as the vastness of fresh and original ideas and observations contained in about 1300 demanding pages, often enough hidden in footnotes, secure it the status of the only reference work on set-theoretical modelling for a long time. 


\section{Appendix: Errata}

The following is a comprehensive list of all formal and mathematical errors and misprints I have found; some other mistakes have also been given if they obscure understanding of the text considerably. The left column shows what is found in the book, the right gives a conjectural amendment.

$293,(2.1 .9 .1)$

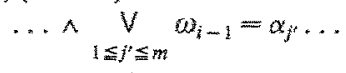

$$
\begin{aligned}
& \ldots \vee \underset{1 \leqslant j^{*} m m}{\wedge} \omega_{i+1}=\alpha_{j^{\prime \prime}} \ldots
\end{aligned}
$$

$$
\left.\left.\left(.4^{4}\right)\right)\right\}
$$

(There are further flaws in the formula. Index $i$ can get out of range; constraints of the type $f_{1} f_{2}=\omega_{i}$ are missing.)

\section{$299,(2.1 .13 .3)$}

(D-congruence does not define a partition of $H^{*}$, because it is not a transitive relation.)

$301,(2.1 .13 .6)$

$\ldots\left(b_{1}, b, b_{2}\right) \in B(h) \ldots$

$350,(2.2 .19 .8)$

(The formula does not yield the desired results. To see this, assume (within the example discussed on the page) $w=$ $w_{1}=t o, w_{2}=$ krasnoe. Union sets of different families can never be families again!)

$$
\begin{aligned}
& \cdots \wedge\left(\underset{1 \leq j^{\prime} \leqq m_{2}}{V} \omega_{i-1}=\alpha_{i} \ldots\right. \\
& \ldots \vee \underset{1 \leq i^{*} \leq m}{\vee} \omega_{k+1}=\alpha_{j *} \ldots \\
& \left.\left.\left.\left(.^{4}\right)\right)^{1}\right)\right\}
\end{aligned}
$$

(Formula must be changed significantly: $B(h)$ (which is a misprint for $B^{J}(h)$ ) is a set of pairs (cf. (2.1.13.4)), not triples.)

$$
\begin{aligned}
& W w^{q i}= \\
& \{w \mid w \in W \wedge \wedge \wedge \\
& \left.\left.K\left(w_{n}\right)=K(w) \Rightarrow \underset{\left.i \leq i, \ldots, w_{n}\right\} \in \mathbb{W}}{\vee} F\left(w_{i}\right)=F(w)\right)\right\}
\end{aligned}
$$

Note: The same mistake occurs in all definitions of quasi-initial elements in the study, i.e., in $(2.3 .6 .1),(2.3 .9 .11),(2.3 .11 .20),(3.3 .12 .5),(4.5 .9 .5),(4.5 .16 .1)$, $(4.6 .22 .8),(5.13 .7),(5.42 .1)$.

350

$$
\begin{aligned}
& \mathrm{F}(\text { krâsnoe }) \rightarrow \mathrm{F}(\dot{e} \text { to }) \quad \text { krásnoe } \rightarrow \text { è่o } \\
& 367,(2.2 .27 .2) \\
& \ldots(i, j)=k^{n}(w) \\
& 423,1.3 \\
& \ldots H^{\prime} \text { is a harp on } W: \ldots \quad \quad \ldots H^{\prime} \text { is a harp on } W^{\prime} \ldots \\
& \text {... by } \mathbf{P}^{*} \\
& 476,(3.2 .12 .4) \\
& \cdots \wedge_{1 \leq k \leq m} \cdots \\
& \ldots \text { by } p^{s} \ldots \\
& \cdots \underset{1<k \leqslant m}{\wedge} \cdots
\end{aligned}
$$$$
426,1.4
$$ 
$486,(3.2 .16 .3)$

The formula contains no less than six errors and must be rewritten as follows:

$506,(3.2 .24 .2)$

The formula does not capture all intended cases, as the nouns $w_{1}, w_{2}$ are assumed not to be defective at the same time here. An improved version is obtained as follows:

528 , last line

$604,1.7$

... $\mathrm{G}^{16}(m g l a \hat{)}) .$.

(4.1.17.5)

$618,(4.1 .24 .1)$

$\cdots \wedge_{1 \leqq k \leqq j} \cdots$

Note: Same flaw in (4.1.36.2).

$621,(4.1 .25 .1)$

$\ldots n^{\prime} \leqq p(h) \vee w=w(n, h) \ldots$
$\mathrm{G}^{9}=$

$\{G \mid G \subset W \wedge \wedge \wedge \wedge \wedge \wedge \wedge \wedge 1 \wedge$

$\left(w_{1}^{\prime} \in \mathrm{G}_{1}^{4} \wedge w_{2}^{\prime} \in \mathrm{G}_{i}^{4}\right) \wedge$

$\wedge \vee \vee \vee \wedge$

$w_{3} \notin G \quad w_{*} \in G \quad w_{3}^{\prime} \in P\left(w_{3}\right) w_{4}^{\prime} \in \mathbb{P}\left(w_{4}\right) G_{j}^{\prime} \in G^{4}$

$\left.\left(w_{3}^{\prime} \notin \mathrm{G}_{j}^{4} \vee w_{4}^{\prime} \notin \mathrm{G}_{j}^{4}\right)\right\}$

Delete '(' before 2nd, add '(' before 3rd quantor; delete 6 th quantor; change all ' $\mathrm{C} 2$ ' to ' $\mathrm{Cl}$ '; make corresponding changes in 3rd and 4th line of formula.

$\ldots \mathrm{G}^{16}(\operatorname{mečtâ}) \ldots$

$(4.1 .17 .6)$

$\cdots \wedge_{\substack{1 \leqq k \leqq j \\ k \leqq p\left(h^{\prime}\right)}}^{\wedge} \cdots$

$\ldots n^{\prime} \leqq p(h) \wedge w=w(n, h) \ldots$

Note: Same mistake in (4.1.29.3), (4.1.36.7)!

$644,(4.1 .36 .3)$ $w(\omega)$ is an undefined function; as far as I can see, $w$ is superfluous.

645 , line 19

After this line, the following must be inserted:

$687,1.5$ from bottom ... power $\operatorname{set}^{1} \boldsymbol{H}^{*}(h)$ of the free monoid ${ }^{2}$ $H^{*}(h) \ldots$

688 , line 6

Set $B^{i}\left(d, d^{\prime}\right)$ which contains the initial substring. .

$688,(4.2 .3 .6)$

$$
\left.\ldots \beta \beta^{\prime} \in h\right\}
$$

$688,(4.2 .3 .8)$

$\ldots\left(B^{i}\left(d_{1}\right) \cap\left(B^{i}\left(d_{2}\right) \neq \emptyset \ldots\right.\right.$

Replace all $w(\omega \ldots)$ by $\omega \ldots$

$\mathbf{\Omega}^{3}(h)=\left\{\Omega \mid \Omega \subset \Omega(h) \wedge \underset{\omega \subset \Omega(h)}{\vee} \Omega=\Omega^{3}(\omega)\right\}$

Then $D^{6}$-dependency is defined as follows:'

... power $\operatorname{set}^{1} \boldsymbol{H}^{*}(\Omega(h))$ of the free monoid ${ }^{2}$ $H^{*}(\Omega(h)) \ldots$

Set $B^{i}(d)$ which contains the initial substrings. . [2 mistakes!]

$\left.\ldots \beta \beta^{\prime}=d\right]$

$691,(4.2 .4 .2)$

$D \in D$.

691, (4.2.4.3)

$\ldots K \subset D^{*} \ldots$

$\ldots\left(B^{i}\left(d_{1}\right) \cap B^{i}\left(d_{2}\right) \neq \emptyset \ldots\right.$

$\ldots D \subset H^{*}(\mathrm{~W}) \ldots$

$\ldots K \subset\left\{D \mid D \subset \Omega^{*}\right\} \ldots$ 


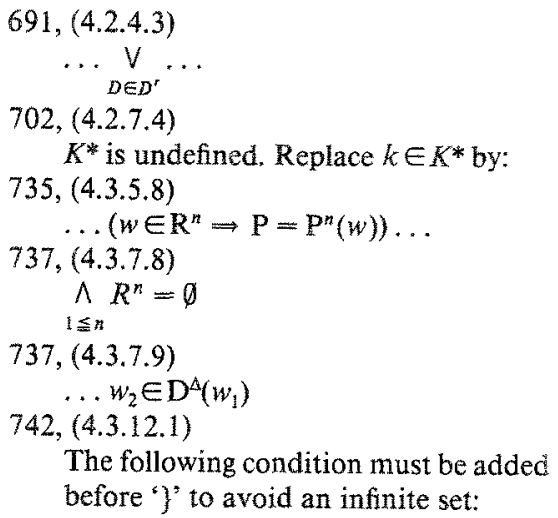

$$
\begin{aligned}
& \ldots \underset{D \in D^{r}}{V} \ldots \\
& k \subset \Omega^{*} \\
& \ldots\left(w \in R^{n} \wedge P=P^{n}(w)\right) \ldots \\
& \wedge R^{n} \neq \emptyset \\
& \ldots w_{2} \notin D^{\Delta}\left(w_{1}\right) \\
& \ldots \wedge \underset{d^{\prime} \in D^{*}}{\vee} p\left(d^{\prime}, w\right)=n
\end{aligned}
$$

Note: The same type of error in (4.3.12.7).

$743,(4.3 .12 .4)$

$$
\begin{aligned}
& \cdots \underset{\left(w_{1}, \ldots, w_{n}\right) \in D^{\text {Nac }}}{V} \underset{1 \leqq i<n}{V}\left(w_{1}=w_{i} \wedge\right. \\
& \cdots \underset{\left(w_{1}^{\prime}, \ldots, w_{n}^{\prime}\right) \in D^{\text {knc }}}{V} \underset{1 \leqq i<n}{V}\left(w_{1}=w_{i}^{\prime} \wedge\right. \\
& \left.\left.w_{2}=w_{i+1}\right)\right\} \\
& \left.\left.w_{2}=w_{i+1}^{\prime}\right)\right\} \\
& 745,(4.3 .14 .1) \\
& \cdots V_{\left\{w_{1}, \ldots, w_{n}\right) \in D^{n}} \cdots \\
& \cdots \underset{\left\{w_{s}, \ldots, w_{n}\right\} \in D^{N x}}{V} \cdots
\end{aligned}
$$

$769,(4.4 .7 .3)$

$$
\left.\left.\ldots(i, j)=k^{d n}(w)\right\} \quad \ldots(i, j)=k^{d n}\left(h_{1}, h_{2}\right)\right\}
$$

811, line 7

...forms that low P-dominate forms...

... forms that bound low P-dominate forms... $842,(4.5 .8 .4)$

$$
\left.\left.\ldots \wedge \mathrm{F}^{\Sigma^{\prime}}(w) \subset \mathrm{F}^{\Sigma^{\prime \prime}}\left(w^{\prime}\right)\right\} \quad \ldots \wedge\left(\mathrm{F}^{\Sigma}(w), \mathrm{F}^{\Sigma^{\prime}}\left(w^{\prime}\right)\right) \in D^{\Sigma^{\prime}}\right\}
$$

$$
\left.\left.\ldots \wedge \mathrm{F}^{\Sigma^{\prime}}\left(w^{\prime}\right) \subset \mathrm{F}^{\mathcal{E}^{\prime \prime}}(w)\right\} \quad \ldots \wedge\left(\mathrm{F}^{\Sigma^{\prime}}\left(w^{\prime}\right), F^{\Sigma^{\prime}}(w)\right) \in D^{\Sigma^{\prime}}\right)
$$

$$
\ldots=\left\{w^{\prime} \mid w \in W \ldots \quad \ldots=\left\{w^{\prime} \mid w^{\prime} \in \mathbb{W} \ldots\right.\right.
$$

856 , line 4 from bottom

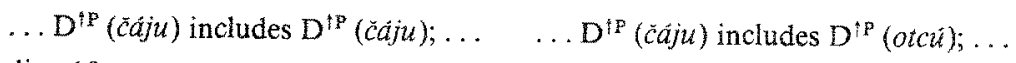

879 , line 10

The set $\Pi^{1 G}(w) \ldots$

914, (4.6.17.6)

$$
\begin{aligned}
\left.\ldots \bigwedge_{c \in C^{G \sigma}} D^{C l}(C, s) \cap W^{a} \neq \emptyset\right\} \quad & \ldots \wedge_{c \in C^{\infty o}}\left(D^{C l}(C, s) \cap W^{a} \neq \emptyset\right. \\
& \left.\left.\vee D^{C l}(C, s)=\emptyset\right)\right\}
\end{aligned}
$$


$914,(4.6 .18 .1)$

$\left.\ldots \wedge w \in \mathrm{W}^{a} \cap \mathrm{D}^{\mathrm{C}}(\mathrm{C}, s)\right\}$

$\left.\ldots \wedge \underset{s^{\prime} \in \mathrm{P}(s)}{\vee} w \in \mathrm{W}^{a} \cap \mathrm{D}^{\mathrm{Cl}}\left(\mathrm{C}, s^{\prime}\right)\right\}$

Note: The above mistake constitutes a confusion between noun word types $(s)$ and the paradigms belonging to them. This flaw reappears in (4.6.25.1), (4.6.27.1); possibly, the paradigm reading was intended at several other places, too.

$935,(4.6 .29 .4)$

$\ldots \mathrm{S}=\overline{\mathrm{S}} \cup \ldots$

$\ldots \overline{\mathrm{S}}=\mathbf{S} \cup \ldots$

946, line 17

... may possess different case systems...

... may possess different gender systems ... 987 , line 5

... agreement in predicates...

$1031,1.4-3$ from bottom $\ldots$ as $\left(k^{\prime},{ }^{\prime} q\right)$, where $\left(k{ }^{\prime}, q^{\prime}\right) \in A^{\mathrm{U}}: \quad \ldots$ as $\left(k, q^{\prime}\right)$, where $\left(k, q^{\prime}\right) \in A^{\mathrm{U}}$ :

1107 , line $21-22$

...(5.4.15) generates the independent...

$1115,1.1-2$

$\ldots$ or accusative...

1122 , lines 5 and 7

' $F\left({ }^{\prime} q\right.$ ')'

$1124,(5.42 .1)$

$F^{\mathrm{K}}$ has not been defined for two arguments. I assume it must be defined as

... agreement in attributive connections... follows:

1125

" have been omitted with $C^{\mathrm{K}}$ several

times.

$1128,(5.46 .9)$

$\left.\ldots F^{\mathrm{K}+}\left(q^{\prime}\right)^{\prime}\right\}$

$1137,(5.50 .1)$

$\ldots C^{\prime} \subset Q^{\prime} \ldots$

$\left.\ldots F^{\mathrm{UK}+}\left({ }^{\prime} q^{\prime}\right)^{\prime}\right\}$

$1153,1.4$ from bottom

$\ldots$ and the nominative.

$1154,1.17$ from bottom

$(5 / 64 / 4)$

$1158,1.18$

... is wholly involved...

$1208,(\mathrm{~B} .6)$

$\ldots(\mathrm{x}) \mid(\mathrm{x}) \wedge \ldots$

$1209,(\mathrm{~B} .7)$

... (( $\left(b . a,{ }^{\prime} \mathrm{q}\right.$ ' $\in \mathrm{T}$...

... (5.33.1) generates the independent ...

$\ldots$ or locative ...

$F^{\mathrm{K}}\left({ }^{\prime} q{ }^{\prime}\right) '$

$F^{\mathrm{K}}\left({ }^{\prime} \mathrm{p}^{\prime}, q^{\prime}\right)=\left\{\left.\left(\mathrm{rr}^{\prime},{ }^{\prime} \mathrm{s}^{\prime}\right)\right|^{\prime} \mathrm{r}^{\prime} \in \mathrm{P}^{\prime} \mathrm{P}^{\prime}\right.$

$s \in Q^{\prime} \wedge \mathrm{W}\left({ }^{\prime} \mathrm{p}^{\prime},{ }^{\prime} q^{\prime}\right)=\mathrm{W}\left({ }^{\prime} \mathrm{r}^{\prime}, \mathrm{s}^{\prime}{ }^{\prime}\right)$

$1209,($ B.7)

$\ldots, \mathrm{a}_{\mathrm{a}, \in \mathrm{T}} \ldots$

$\ldots$ ' $C$ ' $\subset \mathrm{X}^{*}\left(Q^{\prime}\right) \ldots$, where $\mathrm{X}^{*}$ designates

the power set.

... and the accusative.

$(5 / 64 / 1)$

$\ldots$ is only partially involved ...

$\ldots(\mathrm{x}) \mid(\mathrm{x}) \in \mathrm{T} \wedge \ldots$

$\ldots\left(\left(\left(b, a,{ }^{\prime} \mathrm{q}^{\prime}\right) \in \mathrm{T} \ldots\right.\right.$

1209, (B.10)

$\left.\ldots \mathrm{rh}\left({ }^{\prime} \mathrm{g}_{2}{ }^{\prime}\right) \in \mathrm{P}^{\prime} \mathrm{d} \mathrm{d}^{\prime}\right\}$

$\cdots \underset{\mathrm{d} \in \mathrm{F} *}{V} \ldots$

$\left.\ldots \mathrm{rh}\left({ }^{\circ} \mathrm{g}_{2}\right)^{\prime} \in \mathbf{P}^{\prime} \mathrm{d}^{\prime}\right)$ 
Note: In (B.10), ' $\mathrm{y}$ ' and ' $\mathrm{h}$ ' are obviously intended to be homomorphisms. However, no distinction between (semantic) particles as types and as tokens (occuring in a specific configuration) is made, so that (B.10), (B.11), (B.15), (B.23)-(B.25) work correctly only under the counterintuitive premise that in the semantic configurations appearing in these definitions any semantic particle may occur only once.

1211 , line 11

... each consisting of two ordered ... each consisting of two elements... pairs...

$1211,(\mathrm{~B} .17)$

$\left.\left.\cdots \wedge x^{3}={ }^{4} z_{0}{ }^{3}\right)\right\}$

$1211,(\mathrm{~B} .18)$

$\left.\ldots\left(a=z_{1} \vee a=x_{1} \vee a=y_{1}\right)\right\}$

$\left.\ldots \wedge^{6} \mathrm{x}^{\prime}={ }^{\mathrm{t}} \mathrm{x}_{0}{ }^{7}\right\}$

$\left.\ldots\left((a)=\left(z_{1}\right) \vee(a)=\left(x_{1}\right) \vee(a)=\left(y_{1}\right)\right)\right\}$. [This definition still allows for signs larger than words containing words with zero-ending, though this was probably not intended.]

$1211,1.6$ from bottom

Our new set of words consisting of a lexical complex and an ending is: 1211, (B.21)

$$
\left.\cdots \underset{\left(z_{1}\right) \in T_{!}^{z}}{\vee}\left(a=z_{1} \vee a=x_{1} \vee a=y_{1}\right)\right\}
$$

$1218,($ B.37)/(B.38)

These definitions work only if, for any ' $z$ ', there is exactly one $z$ such that $\left(z,{ }^{\prime} z\right) \in T_{1}^{0 M}$, i.e., if synonymy is excluded. For an amendOur new set of strings of $T_{1}$ with a meaning is:

ment, replace $\ldots \mid(z) \in \mathrm{T}_{1}^{0 \mathrm{M}} \ldots$ by: 


\section{NOTES}

1 The Russian term is Теоретикоммножественная икола or IIкола Кулагиной. The term school is somewhat misleading, however. The contributors to the Set-theoretical enterprise formed, according to the author, a loose and unorganized network of researchers, "dispersed over Central and Eastern Europe, and dispersed over various disciplines and types of institutions" (p. 1179), there being no single founder or leader, institutional centre, nor acknowledged reference work of the movement. - The school is associated with the name of O.S. Kulagina, since her only contribution to this field of research, viz., her (1958) paper, is usually claimed to have initiated the school.

2 Kolmogorov is otherwise better known for having, amongst other things, laid the axiomatic foundations of modern probability theory. He never published his own ideas pertaining to linguistics. An account of them was given in an important paper by V.A. Uspenskij (1957/1993).

3 On the term model, see ch. 1.0 of van Helden's book (p. 138-49).

4 Strictly speaking, $\mathbf{F}$ is a function of $N$ into $\mathbf{X}^{*}\left(\mathbf{X}^{*}(C)\right)\left(\mathbf{F}: N \rightarrow \mathbf{X}^{*}\left(\mathbf{X}^{*}(C)\right)\right) ; \mathbf{X}^{*}(M)$ here symbolizes the power set of a set $M$. Moreover, a formalization of the set of word forms for each $n \in N$ is missing in the above discussion. Such a formalization, however, will turn out to be pointless, as the formal notions to be introduced in due course will not depend on such word form sets. I will claim that $\mathbf{F}$ does not hinge upon such sets in any formalizable way. Moreover, I presume $\mathbf{F}$ cannot be further characterized in set-theoretical terms.

5 Here circularity seems to crop up. Note, however, that there is a fundamental difference between 'distinguishing case phenomena from non-case phenomena' and 'determining the set of cases', the former being a necessary prerequisite for the latter.

6 Of course, admission of nouns may be problematic for semantic reasons; see section 2.3 .3 for some notes on grammaticality. My model will also yield reasonable results when a narrow conception of grammaticality is preferred. - Note that, as long as we maintain a naïve concept of 'context', some rather strange results are inavoidable, such as $\mathscr{Q}$ вижу большое ... being grouped as accusative and nominative.

7 The inavoidable permanent change, in any exposition, between the ory-external terms taken from linguistic tradition or 'intuition' in one instance and theory-in ternal terms with a formal definition in the next constitutes a serious problem. It has been solved well by van Helden, who uses technical terms for all of the numerous theory-internal constructs introduced. See also p. 136-7.

8 As is obvious, our formal approach cannot provide us with 1 abels for cases. Any labels we might attribute to them would be completely language-specific (applicable only in this or that concrete situation) or extensional, as van Helden has it (p. 225).

9 The bulk of the work was executed for the preparation of a PhD thesis 1978-1980.

10 Still, some relevant publications have gone unmentioned by the author, e.g. Seidel (1988), Kempgen (1981), or the works of A.K. Polivanova (cf. 1985, 1989, 1990); Bogusławski (1993) and Hubenschmid (1993) appeared too late to be registered.

11 There seem to remain some, though, admittedly, few typos in the reference section. One example I found is Kulagina 1958, which is referred to on p. 1024, not 1028 (see entry on p. 1243).

12 A full-fiedged glossary remains an urgent desideratum for a study as rich and detailed as this one. With the help of the index alone, details (e.g., the discussion of the Estonian comitative and abessive as two putatively identically distributed cases, cf. p. 335), are virtually irretrievable. Sometimes there are inconsistencies: thus, though the opposition of homonymy and syncretism plays an important role in part 5 (vol. II), only the latter term has been included in the index, and only with a reference to vol. I.

Additionally, a list of mathematical symbols as employed in the study would perhaps have been useful. 
13 Thus, van Helden does not introtuce the usual bracket omission conventions for " $V$ ' $A \wedge$ and 'U'/ $\cap$ ', which is necessary to understand, e.g., (1.1.2.25) on p. 157. It should have been mentioned on p. 157 that ' $a \Rightarrow b$ ' is equivalent to ' $-(a \wedge-b)$ '. On p. 163 sqq., the distinction between the terms 'irreflexive' and 'antireflexive' should have been made explicit to avoid misunderstandings.

14 Note, incidentally, that certain variants of Government and Binding (GB) Theory support a relational interpretation. Generally, structural constraints in GB only say whether a given structure is well-formed or not, they do not tell us how to produce them. A case in point is the so-called representational view of Move- $\alpha$ (von Stechow / Sternefeld 1988, 243 sqq.). But even here an algorithmic interpretation, in which the representational view amounts to a recognition syntax, is probably to be preferred.

15 Take the Peano axiomatization for the set $N$ of positive integers, which probably is an instance of a relational model in the author's terminology. Since the Peano axions must be formulated in second-order predicate logic, which is provably incomplete according to $\mathrm{A}$. Church, not all true sentences about positive integers are deducible in a finite number of steps, so that there is no algorithmic model for the properties of $N$ that corresponds to the relational one.

16 It is obvious that the elements of $W$ must be types, not tokens (p. 256).

17 Thus, van Helden implicitly assumes that traditional linguistic concepts are of empirical interest, which is debatable. Note that disentangling the bundles of grammatical features (i.e., identifyng the features themselves) is not so much at stake in part 2 .

18 On p. 424-5, van Helden introduces six different concepts of 'word', making a word form/ lexical meaning / abstract word form distinction on the one hand, and a type / token distinction on the other. This careful differentiation strongly recommends itself for common use in linguistics.

19 One will, of course, run into difficulties with words like бakлyuu and бumb 6akryutu, which no lexical meaning can be attributed to at all (p. 448).

20 See Corbett 1991 for a comprehensive treatment of such phenomena.

21 One of the models presented, viz., Marcus' case model (p. 537-8), is quite similar to the one I proposed above in 1.3, if one takes the $\mathbf{F}(n)$ to be determined directly by the distribution of word forms. My maximality condition, however, tackles context syncretism (p. 540) in an adequate way, in contrast to Marcus' model.

22 Obviously, immediate constituent stnucture analysis has not been explored in the Set-theoretical School, apart from configuration analysis as presented below. This is probably a fleld worth investigating; see Grunig 1981 for a proof that (at least in her axiomatic iramewors) dependency structure turas out to be in st able in the sense that at all "neuralgic points" it 'turns into' constituent structure.

23 The author's definition of $\boldsymbol{g}_{4}$ has been slightly simplified for the purposes of this article.

24 cad and omeu, belong to different agreement classes, but to the same gender, viz., masculine. Though van Helden doesn't make it explicit, it should be obvious that this model is tailored to the specific circumstances found in some Slavic languages, esp. Russian; it would be difficult, if not impossible, to uphold similar distinctions for other, say Bantu or Caucasian, languages. In fact, the bulk of part 4.6 is devoted to this distinction and to a possible semantic core of 'gender" (p. 973 sqq.), taking sentences like mы молодая, where gender assignment is obviously based on natural sex distinctions, as a starting point. Van Helden seriously considers the possibility that gender might be an entirely semantically conditioned phenomenon (p.972), anticipating the semantics discussion in part 5 of the study.

25 Obviously, states abstract from indexical aspects and context-theoretical problens (see Kaplan 1977) as much as objects are conceptualized as deprived of referential properties. Yet it cannot be excluded a priori that case selection might depend exactly on features of referentiality, e.g. with direct objects in negated Russian sentences. There might be serious philosophical difficulties hidden 
here.

26 To be precise, a pair ( $w$, ' $p$ ') is a word form if and only if there is at least one ordered quadruple $m \in M$ such that $\mathrm{w}$ and ' $\mathrm{p}$ ' are its first and third component, respectively.

27 If one thinks of новая and новое as forms of one noun, then this noun would have to be treated analogously to, e.g., иимпанзе (m.f.n.); the whole matter is perhaps a question of taste.

28 The influence of these phonological properties (in particular, underlying final palatalized consonant segment) on the dependent noun cannot be accounted for in terms of the general morphonological properties of Irish, but are specific to this syntactic construction.

29 Another problem, the so-called adprepositional cases of Russian, is discussed at very great length in the study, cf. p. $1076 \mathrm{sqq}$.

30 van Helden does not, in general, count among these grammarians, nor does Jakobson, cf. p. 1219.

31 van Helden himself quite often succumbs to category mistakes, speaking of "states with prepositions" (p. 1140) or of words in states (p. 1141).

32 To name but a few: linguistic signs must be contiguous phoneme chains on the expression plane; inflection of words always involves endings (prefixing is not considered); in the pre-desinential part of a word, the first and last phoneme never change in inflection; in semantic configurations, no semantic atom may occur more than once.

33 I dare say that the two crucial sentences in these lines allow for more than $1024\left(2^{10}\right)$ different readings, a part from quantifier underspecification as acknowledged by van Helden.

34 Would the author, in a future edition of the study, provide explicit answers to at least the following questions about what is said on p. 1151: Are the members of grammatical categories sets of internal meanings or sets of sets of internal meanings? May a state possess more than one set of internal meanings? How on earth can the "equivalence classes" of sets of internal meaning be defined only through 'compatibility with lexemes' and then be elements(!) of grammatical categories? What exactly is supposed to correspond to them in appendix $B$ ?

35 In fact, on p. 1161 he claims that he has assumed "so far" that separate internal meanings are joined into a 'case feature" "when they condition identical behaviour for all nouns" (emphasis mine, P.M.). This plainly contradicts everything said before in the chapter and will strike the reader as incomprehensible. No notion of "identical behaviour" is available for internal case definitions, since identical behaviour can only be defined in distributional terms: Even if no noun has more than two word forms, there might, theoretically, still be any number of different distributional cases, so that word forms alone do not suffice to account for the behaviour of lexemes. Moreover, only lexically determined case systems have been discussed "so far", which is incompatible with a for-all-condition.

36 Consider a hypothetical situation where two different cases of a language occur only as governed by certain prepositions, no preposition goveming both cases.

\section{BIBLIOGRAPHY}

Boas, F.: 1969, "Kwakiutl", in: Boas, F. (ed.): Handbook of American Indian Languages, part 1, Oosterhout N.B. [reprint of the original 1911 edition], 423-557.

Bogusławski, A.: 1993, "A draft theory of inflectional relations (with illustrations from Polish)", in:

Hentschel, G., Laskowski, R. (eds.): Studies in Polish Morphology and Syntax, München, 1-29.

Chomsky, N.: 1957, Syntactic Structures, Den Haag.

Christian Brothers, The: 1991, New Irish Grammar, Dublin.

Corbett, G.G.: 1991, Gender, Cambridge.

Gross, M. / Lentin, A.: 1971, Mathematische Linguistik, Heidelberg, New York. 
Grunig, B.-N.: 1981, Structure sous-jacente: Essai sur les fondements théoriques, [thèse d'état] Lille, Paris.

Hubenschmid, M.: 1993, Genus und Kasus der russischen Substantive, München.

Kaplan, D.: 1977, Demonstratives. An Essay on the Semantics, Logic, Metaphysics, and Epistemology of Demonstratives and Other Indexicals, unpublished paper, Los Angeles.

Kempgen, S.: 1981, "Wortarten" als klassifikatorisches Problem der deskriptiven Grammatik. Historische und systematische Untersuchungen am Beispiel des Russischen, München.

Kratzer, A. / Pause, E. / von Stechow, A.: 1973, Einfithrung in Theorie und Anwendung der generativen Syntax. Erster Halbband: Syntaxtheorie, Frankfurt/M.

Ó Siadhail, M.: 1980, Learning Irish, Dublin.

Pesetsky, D.M.: 1982, Paths and Categories, unpublished MT Diss.

Seidel, H.-E.: 1988, Kasus: Zur Explikation eines sprachwissenschaftichen Terminus (am Beispiel des Russischen), Tübingen.

van Helden, W.A.: 1979, "A model for morphological oppositions", Dutch Contributions to the Eighth International Congress of Slavists, Lisse, 279-93.

von Stechow, A. / Stemefeld, W.: 1988, Bausteine syntaktischen Wissens. Ein Lehrbuch der generativen Grammatik, Opladen.

Vinatrel, G.: 1950, "Staline et les problèmes de linguistique", Réforme 6, 280 [29/7/1950], 7.

Weizsäcker, C.F. von: 1988, Aufbau der Physik, München, Wien.

Кулагина, О.С.: 1958, "Об одном способе определения грамматических понятий на базе теории множеств", Проблемы кибернетики 1, 203-14.

Мельчук, И.А.: 1993, "Сопласование, управление, контруэитность", Вопросы языкознания $34,5,16-58$.

Падучева, Е.В.: 1965, "О понятии конфигурации", Вопросы языкознания 14, 1, 56-68.

Поливанова, A.К.: 1985, "О выборе видовых форм глагола в русском қзыке", Russian Linguistics 9, 209-223.

Поливанова, А.К.: 1989, "Морфолонические объекты в двух лингвистических моделях", Вопросы кибернетики. Семиотинеские исследования, Москва, 38-49.

Поливанова, А.К.: 1990, “Опыт построения грамматической классифихатсии русских лексем", Вопросьі кибернетики, \$зык логики и логика я.зыка, Москва, 41-69.

Успенский, В.А.: 1957/1993, "К определению падежа по А.Н. Колмогорову", Бюллетень обьединения по проблемам маминного перевода 5, 11-8 (corrigenda p. 83); reprint (1993) in the book under review, 1201-6.

Georg-August-Universität Göttingen 